\title{
Trends in the knowledge, attitudes and practices of travel risk groups toward prevention of hepatitis B: Results from the repeated cross-sectional Dutch Schiphol Airport Survey 2002-2009
}

\author{
Perry J.J. van Genderen ${ }^{a, b, *}$, Pieter P.A.M. van Thiel ${ }^{c}$, \\ Paul G.H. Mulder ${ }^{d}$, D. Overbosch ${ }^{\mathrm{a}, \mathrm{b}}$ on behalf of the Dutch \\ Schiphol Airport Study Group
}

\author{
a Institute for Tropical Diseases, Havenziekenhuis, Rotterdam, The Netherlands \\ b Travel Clinic Havenziekenhuis, Rotterdam, The Netherlands \\ c Division of Infectious Diseases and Tropical Medicine and Center for Infection and Immunity Academic \\ Medical Center, University of Amsterdam, Amsterdam, The Netherlands \\ d Department of Biostatistics, Erasmus University Hospital, Rotterdam, The Netherlands
}

Received 11 January 2013; received in revised form 17 September 2013; accepted 19 September 2013 Available online 29 September 2013

\section{KEYWORDS \\ Hepatitis; \\ Travel; \\ Knowledge; \\ Attitude; \\ Practice}

\begin{abstract}
Summary Background: Previous studies investigating the travellers' knowledge, attitudes and practices (KAP) profile indicated an important educational need among those travelling to risk destinations.

Methods: In the years 2002-2009 an annually repeated cross-sectional questionnaire-based survey was conducted at the Dutch Schiphol Airport with the aim to study trends in KAP of travel risk groups toward prevention of hepatitis $B$. The frequently encountered risk groups last-minute travellers, solo-travellers, business travellers, travellers visiting friends and relatives (VFR) and elderly travellers were specifically studied.

Results: A total of 3045 respondents were included in the survey. Travellers to destinations with a high risk for hepatitis B had significantly less accurate risk perceptions (knowledge) than travellers to low-risk destinations but no differences were observed in past risk-taking attitude. Protection rates against hepatitis B were significantly higher in travellers to high-risk destinations. There was a positive trend over the years in the proportion of travellers to high-risk destinations seeking travel health advice. In accordance with this, trend analyses also
\end{abstract}

\footnotetext{
* Corresponding author. Harbor Hospital and Institute for Tropical Diseases, Haringvliet 72, 3011 TG Rotterdam, The Netherlands. Tel.: +31 10 4043305; fax: +31 104121645 .

E-mail addresses: p.van.genderen@havenziekenhuis.nl, pjjvangenderen@travelclinic.com (P.J.J. van Genderen).
} 
indicated rising protection rates against hepatitis B. No significant trends in protection over time were observed for the travel risk groups.

Conclusions: The results of this repeated cross-sectional survey suggest an annual $10 \%$ increase in protection rates against hepatitis $B$ in Dutch travellers, both to destinations with a high risk and to destinations with a lower risk of hepatitis $B$, but these trends in protection rates were not observed for the travel risk groups to high-risk destinations. The KAP profile of last-minute travellers and (to a lesser extent) VFRs showed an increased relative risk in hepatitis B, irrespective of the travel destination, underlining the need for specific targeting of these travel risk groups.

(c) 2013 Elsevier Ltd. All rights reserved.

\section{Introduction}

Even though the risk of hepatitis $B$, a common vaccinepreventable disease, has been best documented in extended-stay travellers like expatriates, short-stay travellers are also at risk and usually unwittingly [1-4]. For example, a study among 1090 Danish travellers who visited hepatitis $B$ endemic countries found that $7 \%$ of travellers were exposed to a possible hepatitis $B$ risk situation, which was either a voluntary risk (1.6\%) such as acupuncture, cosmetic surgery, tattoos, or unprotected sexual contact with local people, or an involuntary risk (5.4\%) such as medical and dental procedures, blood transfusions, or medical aid [5]. Interestingly, a higher proportion of travellers with short trip duration had voluntary risks whereas those with longer trip durations had a higher rate of involuntary risks [5].

In the years 2002-2003 the European Travel Health Advisory Board conducted a cross-sectional pilot survey in several European airports including the Dutch Schiphol Airport to evaluate current travel health knowledge, attitude and practice (KAP) toward prevention of travelrelated infectious diseases like hepatitis B [6]. They found that more than two-third of travellers to developing countries were not vaccinated against hepatitis $B$ [6]. These low immunization rates are in line with the findings of other studies where $57-76 \%$ travelled non-immune (based on immunization history) [5,7]. Speculatively, these data also suggest that many health care providers probably do not routinely offer hepatitis B vaccination to unprotected travellers, even though hepatitis $B$ may pose as a significant exposure-related health risk. In a large UK study, for instance, $12 \%$ of the hepatitis B cases were considered to be acquired during travel with medical treatment abroad and sexual contacts as the most frequently reported routes of transmission [8].

The results of the airport studies also demonstrated an important educational need among those travelling to risk destinations and that all groups of travellers should be targeted. In the Netherlands, the airport survey has been done each year between 2002 and 2009 (except for the year 2006), giving a unique opportunity to study trends in KAP of travellers toward prevention of hepatitis B. Among the travellers, last-minute travellers, solo-travellers, business travellers, travellers visiting friends and relatives (VFR), as well as elderly travellers are thought to belong to groups with an increased risk for travel-related health issues.
These aforementioned frequently encountered travel risk groups were therefore specifically studied. In the present study we report the findings regarding the KAP of these travel risk groups toward prevention of hepatitis $B, a$ vaccine-preventable infectious disease.

\section{Methods}

\section{Questionnaires and survey}

The survey was conducted as previously described [9]. In brief, self-administered, anonymous questionnaires were randomly distributed at the departure gate of Schiphol Airport, Amsterdam, The Netherlands, while passengers were waiting to board. Intercontinental flights to destinations with an intermediate or high risk for hepatitis A, hepatitis B or malaria were preferably selected. The survey was always done in the same period of the year, namely the months October or November. Travellers participated on a voluntary basis; no incentive was provided, except for a leaflet with information on hepatitis $A$, hepatitis $B$ and malaria. Trained interviewers were present to distribute the questionnaires, to answer questions if necessary and to check the completeness of the responses collected. When possible, these interviewers copied the information from the travellers' vaccination records. Travellers were allowed to participate if they were 18 years of age or older, and able to fully understand the language of the questionnaires. They also had to be resident in the Netherlands; thus, nationals of a developing country were only asked to participate if they were actually living in the Netherlands. These criteria were checked by the interviewers when distributing the forms. Afterwards, completed questionnaires from travellers who did not meet all the inclusion criteria were either excluded by the interviewers or rejected from the final analysis.

Two kinds of questionnaires were distributed among the participants, depending on the precise destination. The malaria questionnaire (Q-mal) focused on malaria and its prevention and treatment and these questionnaires were distributed only to travellers with destinations in or close to malaria-endemic areas. The vaccine questionnaire (Q-vacc) targeted hepatitis $A$ and $B$. However, both questionnaires had a common part on personal characteristics (age, gender, nationality, residence, profession), on information regarding the travel (destination, duration, purpose, travel companions) and its preparation, and on the travellers' 
perception of the risk of malaria, hepatitis $A$ and hepatitis $B$ at their destination. In addition, since most malariaendemic countries also carry a high risk for hepatitis A and $\mathrm{B}$, the Q-mal questionnaire also contained several similar items in the Q-vacc questionnaire dealing with the KAP towards prevention of hepatitis $A$ and $B$, which were therefore included in the analysis.

\section{Definitions of risk groups}

Respondents with an age over 60 years were arbitrarily classified as elderly travellers. Solo-travellers were defined as those travellers who travelled alone. Business travellers were defined as those travellers who specifically stated that their main purpose for travel was business-related. Last-minute travellers were defined as those travellers who did not seek pre-travel health advice or sought it only within 2 weeks before departure. Respondents who specifically stated that their main purpose for travel was to visit friends and relatives were considered VFRs.

\section{Determination of KAP profile on hepatitis B}

Knowledge of hepatitis B was determined by comparison of the prevalence of hepatitis $B$ in the country of destination as perceived by the traveller with the actual prevalence of hepatitis B, as depicted in Fig. 1. To that end, all destinations (including those in malaria-endemic countries) were rated as low, intermediate or high-risk destination for hepatitis B based on maps published by the Center for Disease Control, Atlanta, United States of America [10]. Countries with a mixed intermediate-high risk profile (e.g., Brazil) were considered high risk countries since details of the travel within a given country were lacking. For each subject the accuracy (correct risk perception) was expressed as 0 or 1 , with 1 assigned to a subject if his (her) knowledge about risk was compatible with the official risk rating of the destination. To determine the risk-taking attitude of participants, all participants were asked if they at a previous journey: 1. had an injury or accident requiring treatment in hospital (3 points); 2 . had undergone tattooing or piercing during travel (3 points); 3 . had sexual contact with local people (2 points); 4 . had shaving with a local barber (1 point). Each affirmative answer was scored with the designated number of points whereas a negation was scored with 0 points. The final risk-taking attitude score was obtained as the sum of the separate answer scores and could therefore range from 0 to 9; for convenience and without loss of generality, the score was transformed to a $0-100$ scale with the maximal risk attitude score set at 100 . To have an indication of their practice toward prevention of hepatitis $B$ (immunization rate), protection was defined as 0 or 1 , with 1 assigned to travellers with either natural immunity, reporting vaccination for this journey or fully vaccinated in the past (at least 3 doses). Other preventive measures for hepatitis $B$, like actual condom use or single-use needles were not included in the practice scores. In order to estimate the impact of KAP of the travel risk group of interest on relative risk for hepatitis $B$, an aggregate risk estimate was constructed by summing up the effects of the separate determinants. To that end, it was assumed that either a poor risk perception, risk-seeking behaviour or poor protection rates led to an equal increase in relative risk for hepatitis $B$.

\section{Statistical analysis}

Several statistical analyses were made between travellers to high and low-risk destinations. Differences in general characteristics between the two different risk destinations were tested using multiple logistic regression analyses, adjusted for subpopulation (maximally 14 subpopulations:
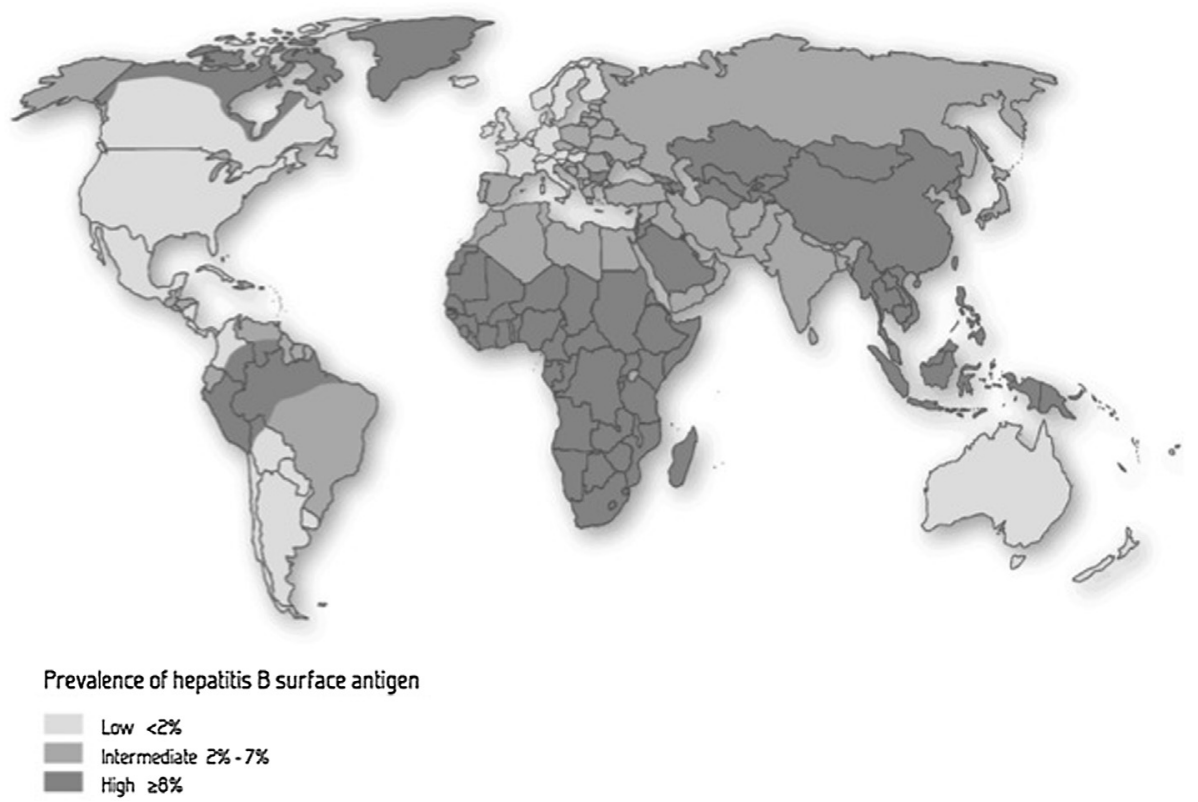

Fig. 1 Prevalence of chronic infection with hepatitis B virus, 2006 (adapted from Map 2-2 for the Center for Disease Control Health information for International Travel (Yellow Book) 2010 [10]). 
two kinds of questionnaires by 7 interview years). Next, logistic regression analyses with adjustment for subpopulation were done for testing differences in risk (e.g., yes vs no VFR as independent variable) between the two knowledge groups (accurate risk perception $\mathrm{y} / \mathrm{n}$ as dependent variable) and the two practice groups (protected $\mathrm{y} / \mathrm{n}$ as dependent variable), allowing separate tests within low and within high-risk destinations through entering the appropriate interaction terms with destination risk into the models (the "within hepatitis B risk destination" analyses). The dependency of the attitude scores on the risk factors was analysed using multiple linear regression analyses, modelled similarly to the above mentioned logistic regression analyses. The regression analyses also allow testing differences between the two risk destination groups in knowledge, attitude and practice within specific risk groups (the "between hepatitis B risk destinations" analyses). By entering the year-by-questionnaire subgroup covariates in the model for explaining knowledge, attitude or practice a properly averaged explanatory effect of the risk factors across the maximally 7 years and two questionnaires was obtained. It was also tested by entering the appropriate interaction terms with time as trend variable in the multiple logistic and linear regression models if the strength of the effect of the predetermined risk factors on knowledge, attitude and practice showed a significant time trend over the years 2002-2009 within low as well as within high-risk destinations. In order to judge how risk factors might have confounded each other in their effects on knowledge, attitude and practice, we calculated the correlations of the risk factors. Additional logistic regression analyses were performed in order to investigate how seeking travel health advice $(y / n)$ and hepatitis B risk destination (high/low) depend on risk factors, adjusted for the year-byquestionnaire subgroups or with year as explanatory time trend variable.

\section{Results}

\section{Study population}

Across all 7 years in the period from 2002 to 2009 (except year 2006) a total of 3050 questionnaires were received, of which 3045 fulfilled the entry criteria and were included in the analysis (Fig. 2). Of the 3045 respondents, 1394 respondents travelled to destinations with a high risk for hepatitis $B$. The remaining 1651 respondents travelled to a low-to-intermediate hepatitis B risk destination. The general characteristics of all respondents, grouped by hepatitis $B$ risk in high and low-to-intermediate risk destinations, are shown in Table 1 . Overall, $46.4 \%$ of responders were female and $53.6 \%$ were male.

\section{Travel profile}

For $20.8 \%$ of the travellers since 2004 it was their first trip to a developing country (there was no first-trip-item in the questionnaires of 2002 and 2003). Overall, 63.9\% indicated tourism as their purpose of travel. One in five to six responders were visiting friends and relatives, business travellers accounted for $15.0 \%$. Few responders travelled for

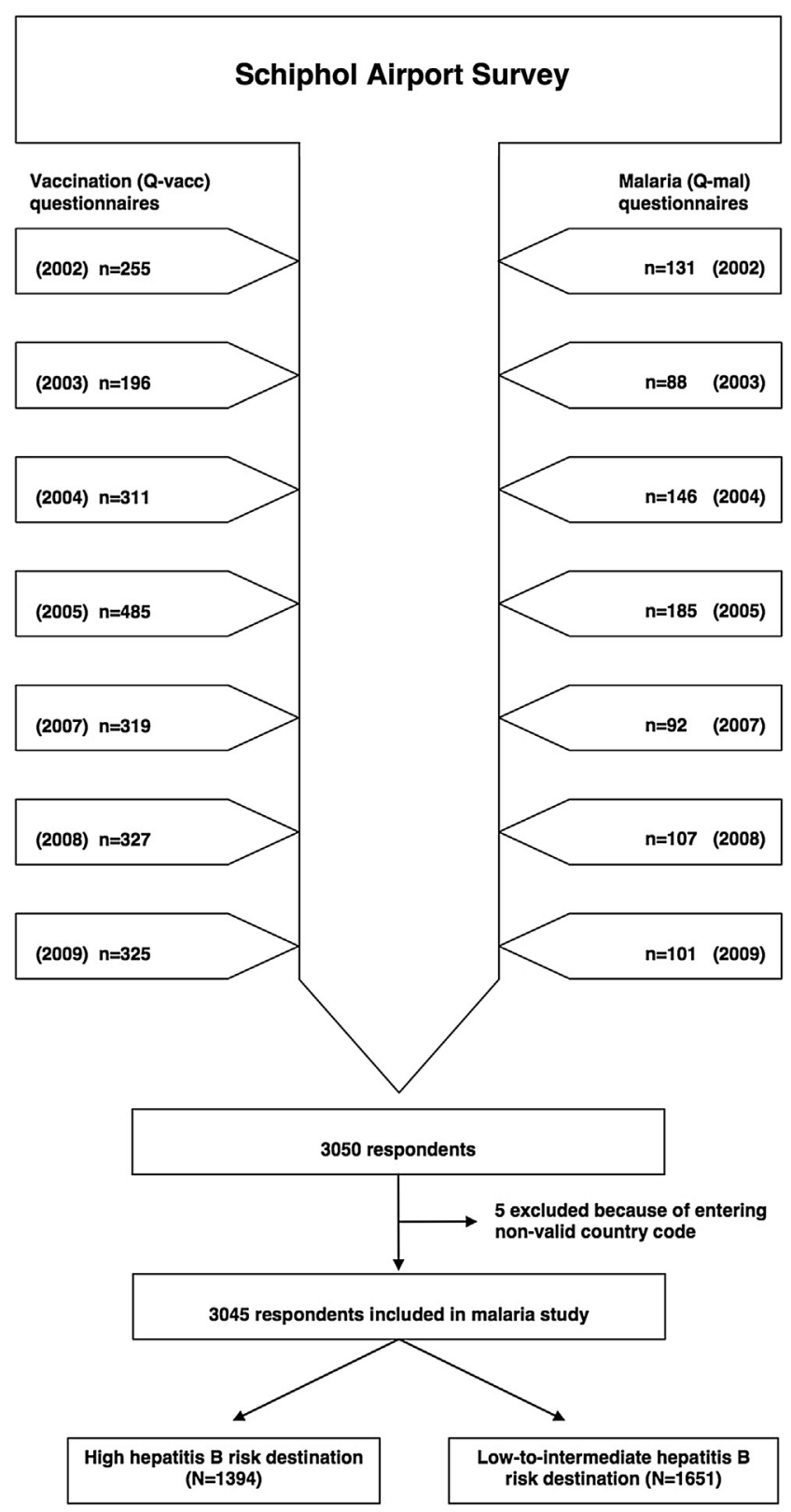

Fig. 2 Flowchart of the Dutch Schiphol Airport Survey. The yearly inclusions of respondents of the malaria questionnaires (Q-mal) and vaccination questionnaires (Q-vacc) in the study are shown as well as reasons for exclusion.

missionary reasons or for voluntary missions $(2.2 \%)$, for purpose of research or education $(0.7 \%)$ or for other reasons (1.0\%). Many travellers (41.6\%) were accompanied by their partner or spouse; 869 persons $(30.3 \%)$ were travelling alone, $6.9 \%$ with friends, $11.7 \%$ with children.

Travellers to high hepatitis $B$ risk destinations planned to stay significantly longer on their destination than travellers to lower-risk destinations ( $p<0.001)$ and obtained pre-travel health advice more frequently prior to departure $(p<0.001)$. Overall, $24.1 \%$ went abroad for $1-7$ days, $40.2 \%$ for $8-14$ days, $26.1 \%$ for $15-28$ days, and $9.5 \%$ for more than 28 days. Gambia was the most common high-risk destination (26.8\%), followed by Thailand (12.6\%) and China (12.3\%) whereas among the low-to-intermediate risk destinations 
Table 1 General characteristics of 3045 respondents in relation to the hepatitis B risk profile of their destination.

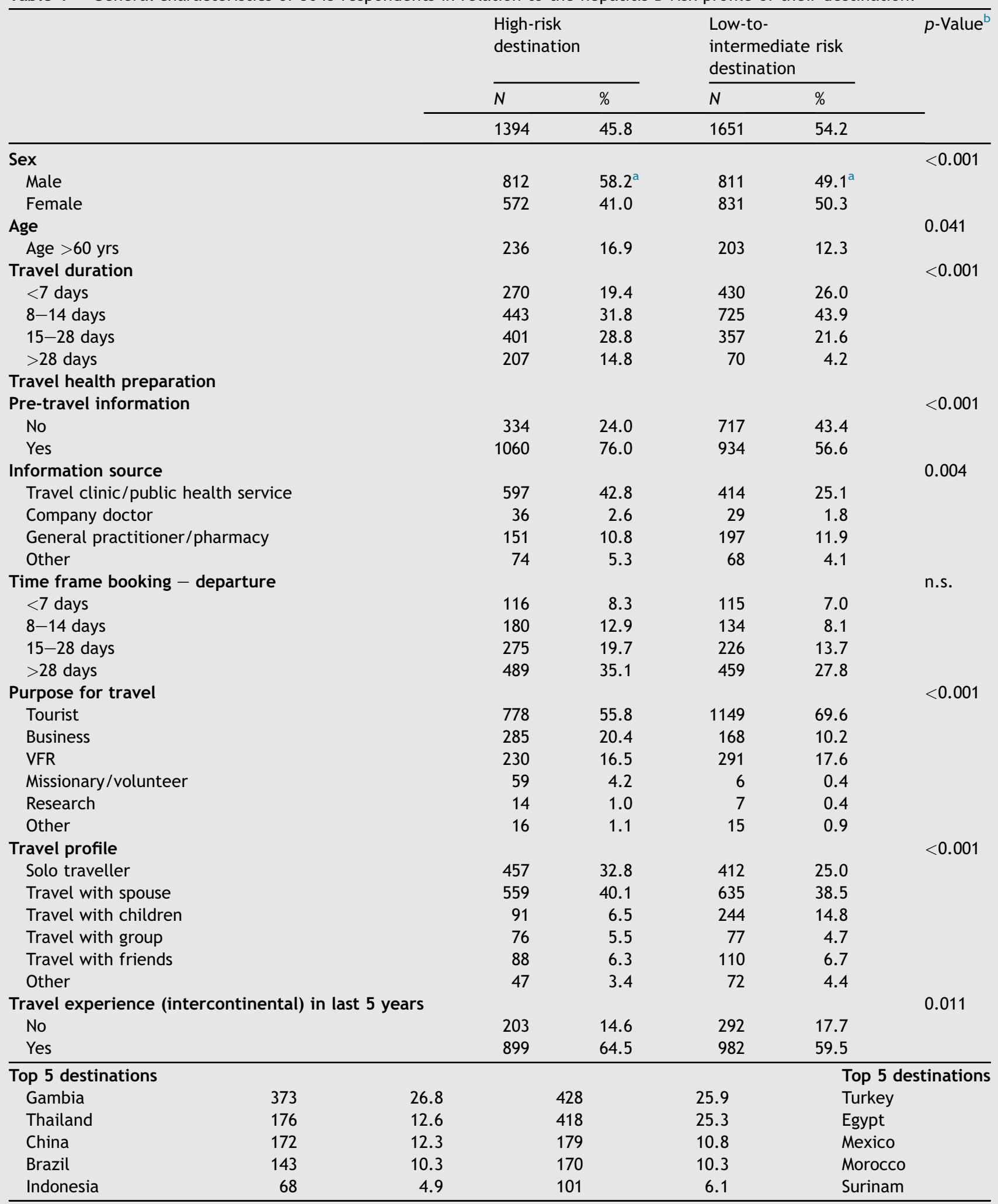

${ }^{a}$ All data are given as a percentage of either the total number of respondents to high-risk destinations (i.e., $\left.n=1394\right)$ or as a percentage of the total number of respondents to low-risk destinations (i.e., $n=1651$ ).

${ }^{b} p$-Value for comparison of high-risk destinations vs low-to-intermediate risk destinations, adjusted for questionnaire type and interview year. 
Turkey $(25.9 \%)$ was the most common destination, followed by the Egypt (25.3\%) and Mexico (10.8\%) (Table 1).

\section{Travel health preparations}

The majority of travellers (65.5\%) had sought health information about their destination prior to departure. This was done more than 1 month before leaving by $47.5 \%$ of the responders; $25.1 \%$ started preparing 2 weeks to 1 month before departure, $15.7 \%$ did so $1-2$ weeks in advance, and $11.6 \%$ did so less than 1 week before leaving.

Of those who had not sought health information, the majority stated that they already knew what to do. The most common sources since 2004 for travel health advice to highrisk destinations were the travel clinic or public health service (42.8\%) followed by general practitioner (GP) or family doctor in $10.8 \%$ of the respondents. For low-risk destinations the travel clinic or public health service was consulted less frequently in $25.1 \%$ of the respondents whereas the GP or family doctor was consulted in $11.9 \%$ of the cases $(p=0.004)$. In the 2002- and 2003-questionnaires there was no item concerning source of advice. There was a significant positive trend over the years in the proportion of travellers to high-risk destinations seeking travel health advice (odds ratio 1.21 per year; $95 \% \mathrm{Cl}$ : 1.07-1.37; $p=0.002$ ), adjusted for questionnaire type, VFR traveller, elderly traveller, business traveller, solo traveller and length of travel.

\section{Travel risk groups}

The group of elderly travellers comprised 439 respondents. Of them, $236(16.9 \%)$ travelled to a high-risk destination. The group of last-minute travellers comprised of 545 respondents; $296(54.3 \%)$ of them travelled to a high-risk destination. Of all respondents, 869 respondents travelled alone and were classified as solo-travellers; 457 (52.6\%) of them travelled to a high-risk destination. The group of business travellers consisted of 453 individuals of whom 285 (62.9\%) travelled to destinations rated as a high-risk destination. The group of VFRs consisted of 521 respondents; 230 (44.1\%) of them travelled to a high-risk destination (Table 1).

\section{Knowledge, attitude and practice on hepatitis B}

\section{Analysis of risk groups}

\section{Elderly travellers}

Elderly aged travellers visited high-risk destinations significantly more frequently (Table $1: p=0.041$, adjusted for subpopulation) than younger aged travellers. Elderly travellers to either high-risk or low-risk destinations did not seek pre-travel information significantly more often than younger aged travellers to the same risk destination ( $p=0.39$ for low risk and $p=0.52$ for high-risk destinations, adjusted for subpopulation). The knowledge, attitude and practice of elderly travellers to high-risk destinations were comparable to that of younger travellers to same risk destinations (Table 2). As a consequence, as shown in Table 3, the relative risk of elderly travellers for hepatitis B was comparable with that of younger travellers.

\section{Solo-travellers}

Solo-travellers travelled to high-risk destinations more often than non-solo-travellers (odds ratio $1.84(95 \% \mathrm{Cl}$ : $1.54-2.19 ; p<0.0005)$, adjusted for subpopulation). Solotravellers to either high $(p<0.0005)$ or low-risk destinations $(p<0.0005)$ had less preparation for their travel than non-solo-travellers to the same risk destination (respective odds ratios (95\% Cl's): $0.52 \quad(0.40-0.68)$ and 0.49 (0.39-0.62), adjusted for subpopulation). The risk perception of solo-travellers to high-risk destinations was comparable to that of non-solo-travellers, whereas past risk-taking behaviour and protection rates were significantly higher (Table 2). As a consequence, the KAP of solotravellers to high-risk destinations did not change the relative risk for hepatitis B (Table 3 ).

\section{Business travellers}

Business travellers to either high $(p<0.0005)$ or low-risk destinations $(p<0.0005)$ less frequently sought travel health advice than non-business travellers (respective odds ratios (95\% Cl's): 0.48 (0.35-0.64) and 0.47 (0.34-0.66), adjusted for subpopulation). Business travellers travelled more frequently to high-risk destinations than non-business travellers (odds ratio 2.88; $95 \% \mathrm{Cl}: 2.28-3.63 ; p<0.0005$, adjusted for subpopulation). Business travellers to high-risk destinations had comparable knowledge and risk-taking attitude as non-business travellers but had significantly higher protection rates against hepatitis $\mathrm{B}$. As a consequence, the KAP of business travellers to high-risk destinations slightly decreased their relative risk for hepatitis B (Table 3).

\section{Last-minute travellers}

Last-minute travellers went significantly less to high hepatitis $B$ risk destinations than regular travellers (odds ratio $0.70 ; 95 \% \mathrm{Cl}: 0.59-0.82 ; p<0.0005$, adjusted for subpopulation) and had comparable travel health preparation in comparison to regular travellers when travelling to high-risk destinations $(p=0.35)$. When travelling to lowrisk destinations, regular travellers consulted the regular health authorities (GP, company doctor, chemist, municipal health service) more often than last-minute travellers did (93.8\% vs $83.0 \% ; p<0.0005$, adjusted for subpopulation). The risk perception and protection rates of last-minute travellers to high-risk destinations were significantly lower than that of regular travellers (Table 2). In addition, lastminute travellers to high-risk destinations had comparable past risk-taking behaviour than regular travellers. As a consequence, the KAP of last-minute travellers to high-risk destinations substantially increased their relative risk for hepatitis B (Table 3).

\section{VFRs}

VFRs sought less frequently travel health advice than non-VFR travellers when travelling to low-risk destinations (odds ratio 0.50; 95\% Cl: 0.38-0.65; $p<0.0005$, adjusted for subpopulation). For high-risk destinations there was no significant effect of VFR on seeking health advice 
Table 2 Knowledge, attitude and practices of travel risk groups to destinations with high and low-to-intermediate risk for hepatitis B.

\begin{tabular}{|c|c|c|c|c|c|c|c|c|c|c|c|c|}
\hline \multirow[t]{2}{*}{ Knowledge $^{a}$} & \multicolumn{6}{|c|}{ High-risk destinations } & \multicolumn{5}{|c|}{ Low-to-intermediate risk destinations } & \multirow{2}{*}{$\begin{array}{l}p \text {-Value (high vs } \\
\text { low-risk } \\
\text { destinations }^{\mathrm{f}} \text { ) }\end{array}$} \\
\hline & \# cases & \multicolumn{2}{|c|}{ \# total } & $\%$ & $\begin{array}{l}p \text {-Value(within } \\
\text { high-risk } \\
\text { destinations }^{\mathrm{d}} \text { ) }\end{array}$ & $\begin{array}{l}95 \% \text { confidence } \\
\text { interval of } \%\end{array}$ & \# cases & \# total & $\%$ & $\begin{array}{l}p \text {-Value (within } \\
\text { low-risk } \\
\text { destinations }^{\mathrm{e}} \text { ) }\end{array}$ & $\begin{array}{l}\text { 95\% confidence } \\
\text { interval of } \%\end{array}$ & \\
\hline Overall & 343 & 13 & & 24.6 & n.a. & $22.4-27.0$ & 774 & 1651 & 46.9 & n.a. & $44.4-49.3$ & $<0.001$ \\
\hline Elderly traveller & 67 & & & 28.4 & n.s. & $22.7-34.6$ & 81 & 203 & 39.9 & 0.018 & $33.1-47.0$ & 0.001 \\
\hline Solo-traveller & 135 & & & 24.8 & n.s. & $21.2-28.6$ & 214 & 465 & 46.0 & n.s. & $41.4-50.7$ & $<0.001$ \\
\hline Business-traveller & 74 & & & 25.7 & n.s. & $20.7-31.2$ & 88 & 169 & 52.1 & n.s. & $52.1-59.8$ & $<0.001$ \\
\hline Last-minute traveller & 129 & & & 20.5 & 0.007 & $17.4-23.8$ & 398 & 966 & 41.2 & $<0.001$ & $38.1-44.4$ & $<0.001$ \\
\hline VFR & 57 & & & 24.8 & n.s. & $19.3-30.9$ & 115 & 291 & 39.5 & 0.011 & $33.9-45.4$ & $<0.001$ \\
\hline Attitude $^{\mathrm{b}}$ & $n$ & Mean & SD & $\begin{array}{l}p-1 \\
\text { hig } \\
\text { de }\end{array}$ & $\begin{array}{l}\text { lue (within } \\
\text {-risk } \\
\text { inations }{ }^{\mathrm{d}} \text { ) }\end{array}$ & $\begin{array}{l}95 \% \text { confidence interva } \\
\text { of mean }\end{array}$ & $n$ & Mean & SD & $\begin{array}{l}p \text {-Value (within } \\
\text { low-risk } \\
\text { destinations }^{\mathrm{e}} \text { ) }\end{array}$ & $\begin{array}{l}95 \% \text { confidence } \\
\text { interval of mean }\end{array}$ & $\begin{array}{l}p \text {-Value (high vs } \\
\text { low-risk } \\
\text { destinations }^{f} \text { ) }\end{array}$ \\
\hline Overall & 899 & 7.1 & 14.3 & n.a & & $6.1-8.1$ & 982 & 5.9 & 13.3 & n.a. & $5.1-6.7$ & n.s. \\
\hline Elderly traveller & 178 & 6.4 & 13.0 & n.s & & $4.5-8.3$ & 126 & 4.0 & 10.6 & 0.047 & $2.1-5.9$ & n.s. \\
\hline Solo-traveller & 382 & 9.4 & 16.9 & & & 7.7-11.1 & 310 & 8.2 & 14.9 & 0.002 & $6.5-9.9$ & n.s. \\
\hline Business-traveller & 219 & 6.6 & 14.6 & n.s & & $4.6-8.6$ & 120 & 4.1 & 10.1 & n.s. & $2.3-5.9$ & n.s. \\
\hline Last-minute traveller & 438 & 7.6 & 15.0 & n.s & & $6.2-9.0$ & 601 & 6.2 & 12.9 & n.s. & $5.1-7.3$ & n.s. \\
\hline VFR & 118 & 13.2 & 18.7 & $<0$ & & $9.8-16.6$ & 159 & 11.7 & 17.1 & $<0.001$ & $9.0-14.4$ & n.s. \\
\hline Practice $^{c}$ & \# cases & & & $\%$ & $\begin{array}{l}p \text {-Value (within } \\
\text { high-risk } \\
\text { destinations }^{d} \text { ) }\end{array}$ & $\begin{array}{l}95 \% \text { confidence } \\
\text { interval of } \%\end{array}$ & \# cases & \# total & $\%$ & $\begin{array}{l}p \text {-Value (within } \\
\text { low-risk } \\
\text { destinations }^{\mathrm{e}} \text { ) }\end{array}$ & $\begin{array}{l}95 \% \text { confidence } \\
\text { interval of } \%\end{array}$ & $\begin{array}{l}p \text {-Value (high vs } \\
\text { low-risk } \\
\text { destinations }^{f} \text { ) }\end{array}$ \\
\hline Overall & 319 & 720 & & 44.3 & n.a. & $40.6-48.0$ & 512 & 1483 & 34.5 & n.a. & $32.1-37.0$ & $<0.001$ \\
\hline Elderly traveller & 50 & 121 & & 41.3 & n.s. & $32.4-50.6$ & 70 & 171 & 40.9 & n.s. & $33.5-48.7$ & n.s. \\
\hline Solo-traveller & 165 & 325 & & 50.2 & 0.003 & $44.6-55.7$ & 155 & 436 & 35.6 & n.s. & $31.1-40.2$ & $<0.001$ \\
\hline Business-traveller & 99 & 185 & & 53.5 & 0.001 & $46.0-60.9$ & 70 & 168 & 41.7 & 0.006 & $34.1-49.5$ & 0.044 \\
\hline Last-minute traveller & 132 & 368 & & 35.9 & $<0.001$ & $31.0-41.0$ & 257 & 893 & 28.8 & $<0.001$ & $25.8-31.9$ & 0.007 \\
\hline VFR & 55 & 125 & & 44.0 & n.s. & $35.1-53.2$ & 63 & 247 & 25.5 & 0.001 & $20.2-31.4$ & $<0.001$ \\
\hline
\end{tabular}

All $p$-Values corrected for questionnaire type and interview year. n.a. $=$ not applicable; n.s. $=$ not significant. Last-minute $=$ information sought: none or within 14 days before departure.

a Knowledge was defined as a binary $0 / 1$ score (no/yes accurate risk perception); cases were defined as those individuals with accurate risk perception (score 1).

b Attitude was defined as a continuous risk behaviour score on a $0-100$ scale.

c Practice was scored only in the vaccination questionnaires as a binary $0 / 1$ score (no/yes protected); cases were defined as protected individuals (score 1 ).

$d p$-Value of comparison of a given risk group vs the remainder of travellers to a high-risk destination.

e $p$-Value of comparison of a given risk group vs the remainder of travellers to a low-to-moderate risk destination.

${ }^{f} p$-Value of comparison of a given risk group to a high-risk destination vs the same risk group to a low-to-intermediate risk destination. 
( $p=0.53$, adjusted for subpopulation). There was also no significant difference in destination-risk between VFRs and non-VFR travellers ( $p=0.16$, adjusted for subpopulation). The knowledge and practice of VFRs toward prevention of hepatitis B were comparable to that of non-VFR travellers to high-risk destinations. However, VFRs had significantly higher risk-taking behaviour in the past than non-VFR travellers to high-risk destinations (Table 2). As a consequence, the KAP profile of VFRs slightly increased their relative risk for hepatitis $B$ (Table 3 ).

Trends in knowledge, attitudes and practices of travellers toward prevention of hepatitis B

\section{Knowledge (accurate risk perception)}

Over the years there was no significant trend in knowledge for all travellers to high-risk destinations in contrast to all travellers to a lower-risk destination in whom the knowledge-odds increased by $6.2 \%$ per year $(p=0.004 ; 95 \% \mathrm{Cl} 1.9-10.6)$. Of the travel risk groups, only in last-minute travellers to low-tointermediate risk destinations, a significant downward trend of $8.6 \%$ per year in the knowledge-odds was observed over the years $(p=0.034 ; 95 \% \mathrm{Cl}:-15.8 \%$ to $-0.7 \%)$.

\section{Attitude (past-risk taking behaviour)}

In travellers to high-risk destinations trend analysis did not show a significant trend over the years, neither overall nor in any of the predefined risk groups. In contrast, there was a significant overall downward trend of -0.48 points per year in attitude score (scale 0-100) in travellers to lowto-intermediate risk destination $(95 \% \mathrm{Cl}:-0.95$ to -0.02 ; $p=0.041)$. Also in VFR travellers to low-to-intermediate risk destinations a significant downward trend in attitude score of -1.41 points per year was observed $(95 \% \mathrm{Cl}:-2.79$ to $-0.03 ; p=0.045$ )

\section{Practice (protection rate)}

In both travellers to high-risk destinations and travellers to low-to-intermediate risk destinations a significant positive trend in protection was observed (high-risk destinations: $9.6 \%$ increase in the protection-odds per year (95\% Cl: 2.4-17.4; $p=0.008$ ); lower-risk destinations: $9.5 \%$ increase in the protection-odds per year (95\% Cl 4.6-14.6)). There were no significant trends observed in protection of any of the travel risk groups to either high-risk or lower-risk destinations.

\section{Discussion}

The results of the European Airport Survey demonstrated an important educational need among those travelling to risk destinations and it was suggested that travel health advice providers should continue their efforts to make travellers comply with the recommended travel health advice, especially risk groups [6]. The present study provides indepth feedback on these efforts toward prevention of hepatitis B by analysing the trends in KAP of Dutch travellers, including those belonging to a certain risk group, over an 8-year observation period.

The results of the current airport study demonstrate that the immunization rates of hepatitis B of Dutch travellers to a high-risk destination is $44.3 \%(95 \% \mathrm{Cl}$ : 40.6-48.0) which seems comparable to that reported for Danish travellers (43\%) [5] and higher than that reported for Swedish (34\%), American (29\%) and Australian (28\%) travellers $[7,11,12]$. However, the definitions of immunity may have varied between these studies which should be taken into account before drawing definite conclusions. It is certainly noteworthy that a significant trend toward rising immunization rates over time was observed for the average Dutch traveller, both to high-risk and lower-risk destinations.

During the study period, the Netherlands had a program of targeted HBV risk group vaccination rather than universal vaccination as is practiced in most other countries in the world. These improved immunization rates may therefore reflect the continuous efforts of Dutch travel health advice providers to propagate safe and healthy travel. The rising trend in travellers to high-risk destination seeking health advice before commencing travel is in line with this. Additionally, the observation that in Dutch travellers the immunization coverage of hepatitis $A$

Table 3 Estimates of the aggregated impact of the knowledge, attitude and practices (KAP) of travel risk groups on their relative risk of hepatitis $B$.

\begin{tabular}{|c|c|c|c|c|}
\hline Risk group & Knowledge & Attitude & Practice & Impact on relative risk of hepatitis $B$ \\
\hline \multicolumn{5}{|c|}{ Destinations with a known high risk of hepatitis B } \\
\hline Elderly traveller & No effect on risk & No effect on risk & No effect on risk & No effect on risk \\
\hline Solo traveller & No effect on risk & Increase in risk & Decrease in risk & No effect on risk \\
\hline Business traveller & No effect on risk & No effect on risk & Decrease in risk & Slight decrease in risk \\
\hline Last-minute traveller & Increase in risk & No effect on risk & Increase in risk & Moderate increase in risk \\
\hline VFR & No effect on risk & Increase in risk & No effect on risk & Slight increase in risk \\
\hline \multicolumn{5}{|c|}{ Destinations with a known low-to-intermediate risk of hepatitis B } \\
\hline Elderly traveller & Increase in risk & Decrease in risk & No effect on risk & No effect on risk \\
\hline Solo traveller & No effect on risk & Increase in risk & Decrease in risk & No effect on risk \\
\hline Business traveller & No effect on risk & No effect on risk & No effect on risk & No effect on risk \\
\hline Last-minute traveller & Increase in risk & No effect on risk & Increased in risk & Moderate increase in risk \\
\hline VFR & Increase in risk & Increase in risk & Increase in risk & Substantial increase in risk \\
\hline
\end{tabular}


increased in parallel over time, [9] further strengthens this relationship.

When focussing on the travel risk groups, our results indicated that the KAP of last-minute travellers, in particular those travelling to high-risk destinations, substantially increased their relative risk for hepatitis B. For destinations with a lower hepatitis B risk this was the case with VFR travellers and - to a lesser extent - last-minute travellers. Whether or not advising hepatitis B immunization to the short-term traveller remains a subject of continuous debate. In a previous retrospective study, Sonder and colleagues [13] investigated the incidence and risk factors for hepatitis $B$ infection in travellers from Amsterdam, The Netherlands and found a low incidence of 4.5 per 100,000 travellers. They argued that vaccination was not deemed necessary for everyone given the fact that only a small proportion of those considered to be "at risk" according to behavioural studies actually do acquire the disease. This point of view is, however, refuted by others who claim that even if the risk to the individual traveller from a single trip is low, many infections are expected to continue to pose risks to travellers during subsequent travel $[5,14]$. In addition, administering immunizations like hepatitis B at an older age may be associated with lower seroconversion rates due to immunosenescence. A clear advantage of considering an aggregate risk approach is that previous vaccination would circumvent many of the potential problems associated with last-minute travel, including unexpected changes to itineraries and departure and induction of immunological memory but also requires discipline for completion of immunization schedules after a single travel $[14,15]$.

Even though the current study focused on travel destinations with a high risk of hepatitis $B$, lower-risk destinations may also pose a threat to the unprotected traveller. A large UK study of hepatitis B incidence and transmission demonstrated that $12 \%$ of the hepatitis $B$ cases were considered travel-related but that almost half of the cases (45\%) were acquired after travel to a medium endemicity country [8]. The results of our Airport study suggested that of the travellers to lower-risk destinations, in particular those visiting friends and relatives and last-minute travellers are at an increased (relative) risk of hepatitis $B$, which may provide an extra argument for vaccination.

Interestingly, after completion of this study, the Netherlands have changed their national childhood vaccination programme by starting vaccinating all babies born on or after the first of August 2011 against hepatitis B [16]. The immunization rates against hepatitis $B$ of future Dutch travellers are therefore likely to increase further. Unfortunately, the Dutch government decided not to institute a catch up immunization campaign for children born before this date [16]. As a consequence for the near future, Dutch travel health care providers still have to consider the possibility of unprotected children and adolescents travelling to hepatitis $B$ risk destinations.

\section{Limitations}

Questionnaire-based surveys may have several drawbacks which may limit the generalizability of the current findings. First, cross-sectional questionnaire-based surveys do not allow the evaluation of the impact of KAP on actual incidence of hepatitis B cases among travellers during the study period. In addition, risks for acquiring hepatitis B may vary within a country and with each possible hepatitis $B$ risk situation like unprotected sexual contact. We can therefore not truly speak of risk of hepatitis $B$ but have to confine to relative risks instead. Second, the classification of practice is based on immunization rates but not on post-vaccination titres. As a consequence, it is assumed that only vaccination results in protection against hepatitis B but this may not be the case for non-converting individuals and neglects the impact of other preventive measures like condom use. Third, the estimation of risk-taking or risk-avoiding behaviour was based on previous journeys but attitudes may change over time and may differ per journey. Further, this study was designed to study the KAP of certain frequently encountered travel risk groups to destinations with a high or lower risk for hepatitis B and all destinations were selected to meet this requirement. The destinations were not randomly selected from all available risk destinations. In addition, the survey was always done in the months October and November of each year, which may have introduced a selection bias since people who travel at this time of year may differ from people who travel during other periods. Moreover, one could argue that the traveller's KAP profile including those belonging to risk groups may be influenced by their prior travel experience. To specifically address this potential confounder, all questionnaires since 2004 contained questions elaborating on this item. It appeared that as of 2004 travellers to high-risk destinations had more prior travel experience than travellers to lower-risk destinations (odds ratio of prior travel experience: $1.36 ; 95 \% \mathrm{Cl}$ : 1.07-1.72; $p=0.011$, adjusted for subpopulation). Lastly, not all respondents belonged mutually exclusive to one risk group; this might theoretically have confounded the effect attributed to a certain characteristic of a risk profile without adjusting for the other characteristics. For judging potential mutual confounding of the travel risk factors in their effect on KAP we calculated all correlations between the risk factors; as the stronger correlations differ from zero, the more confounding there may be. It appeared that the only relevant correlation found was that between business and solo-travellers $(r=+0.59)$. All other pairwise correlations were near zero (varying between -0.19 and +0.16 ). This means that the effect of business travelling on KAP partly includes the effect of solo travelling on KAP and vice versa, while between all other pairs of risk factors there will be hardly any confounding. However, the interest of our study focused on identifying travel risk groups rather than theoretically disentangling the effects of the various risk characteristics. The present study was also not designed to study the KAP of long-term travellers toward hepatitis B. All travellers with a travel duration exceeding 4 weeks were grouped in this study, whereas hepatitis $B$ vaccination is usually advised for travel duration exceeding $>3$ months. However, as compared to travel $<4$ weeks, travellers with a travel duration of 4 weeks or more had significantly more past-risk taking behaviour $(14.4(95 \% \mathrm{Cl}$ 
11.2-17.6)) but significantly higher protection rates (52.8\% (95\% Cl 44.3-61.2\%)), suggesting that these opposite effects on KAP cancel each other out (data not shown).

In conclusion, the results of this repeated cross-sectional survey suggest an annual $10 \%$ increase in immunization rates against hepatitis $B$ in Dutch travellers, both to destinations with a high risk and a lower risk of hepatitis $B$, but these promising trends were not observed in the predefined travel risk groups to high-risk destinations. The KAP profile of lastminute travellers and (to a lesser extent) VFRs increased their relative risk for hepatitis $B$, irrespective of the travel destination, underlining the continuous need for specific targeting of particularly these travel risk groups.

\section{Conflict of interest}

PJJvG and DO received speaker's fee and reimbursements for attending symposia from GlaxoSmithKline. The others have no conflict of interest to declare.

\section{Acknowledgements}

This study was done with financial and logistic support from GlaxoSmithKline. Mr. Michiel Vervoort is acknowledged for construction of Fig. 2. Members of the Dutch Schiphol Airport Study Group are: Perry J.J. van Genderen, MD, PhD (Havenziekenhuis, Rotterdam); Paul G.H. Mulder, PhD (Erasmus University, Rotterdam); Christian Hoebe, MD, PhD (GGD, Maastricht); Sietse Felix, MD (KLM Health Services, Amsterdam); Pieter van Thiel, MD, PhD (Academic Medical Center, Amsterdam) and David Overbosch, MD, PhD (Travel Clinic Havenziekenhuis, Rotterdam).

\section{References}

[1] Jong EC. Risk of hepatitis A and B in the travelling public. J Travel Med 2001;8(Suppl.):S3-8.

[2] Zuckerman JN, Steffen R. Risks of hepatitis B in travellers as compared to immunization status. J Travel Med 2000;7:170-4.

[3] Steffen R. Risks of hepatitis B for travellers. Vaccine 1990;8: S31-2.
[4] Zuckerman JN, Hoet B. Hepatitis B immunization in travellers: poor risk perception and inadequate protection. Travel Med Infect Dis 2008;6:315-20.

[5] Nielsen US, Petersen E, Larsen CS. Hepatitis B immunization coverage and risk behavior among Danish travellers: are immunization strategies based on single journey itineraries rational? J Infect 2009;59:353-9.

[6] Van Herck K, Castelli F, Zuckerman J, et al. Knowledge, attitudes and practices in travel-related infectious diseases: the European Airport Survey. J Travel Med 2004;11:3-8.

[7] Dahlgren AL, DeRoo L, Steffen R. Prevention of travel-related infectious diseases: knowledge, practices and attitudes of Swedish travellers. Scand J Infect Dis 2006;38:1074-80.

[8] Hahne S, Ramsay M, Balogun K, et al. Incidence and routes of transmission of hepatitis B virus in England and Wales, 1995-2000: implications for immunization policy. J Clin Virol 2004;29:211-20.

[9] Van Genderen PJ, van Thiel PP, Mulder PG, Overbosch D., on behalf of the Schiphol Airport Study Group. Trends in knowledge, attitude and practices of travel risk groups toward prevention of hepatitis A: results from the Schiphol Airport Survey 2002-2009. J Travel Med 2012;19:35-43.

[10] Centers for Disease Control and Prevention. CDC health information for international travel 2010. New York: Oxford University Press; 2010.

[11] Connor BA, Jacobs RJ, Meyerhoff AS. Hepatitis B risks and immunization coverage among American travellers. J Travel Med 2006;13:273-80.

[12] Leggat PA, Zwar NA, Hudson BJ., on behalf of the Travel Health Advisory Group, Australia. Hepatitis B risks and immunisation coverage amongst Australians travelling to southeast Asia and east Asia. Travel Med Infect Dis 2009;7: 344-9.

[13] Sonder GJB, van Rijckevorsel GGC, van den Hoek A. Risk of hepatitis B for travellers: is vaccination for all travellers really necessary? J Travel Med 2009;16:18-22.

[14] Leder K, Chen LH, Wilson ME. Aggregate travel vs. single trip assessment: arguments for cumulative risk analysis. Vaccine 2012;30:2600-4.

[15] Zuckerman JN, van Damme $P$, van Herck K, Loscher T. Vaccination options for last-minute travellers in need of travel-related prophylaxis against hepatitis A and B and typhoid fever: a practical guide. Travel Med Infect Dis 2003; 1:219-26.

[16] Rijksoverheid website. Available at: http://www. rijksoverheid.nl/documenten-en-publicaties/kamerstukken/ 2010/07/22/algemene-vaccinatie [accessed 01.01.2013]. 